I08. Apical abscissa of the submarginal vein much longer than thick ?gen. ${ }^{1}$ Apical abscissa of the submarginal vein not or only a little longer than thick First joint of the flagellum never much longer than the second, often

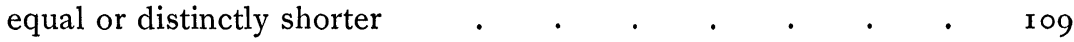
First joint of the flagellum very long, stout, usually curved and as long or nearly as long as joints 2 and 3 united . . . . . ? gen. ${ }^{1}$ rog. First joint of the flagellum about as long as the second or only a little longer, the second shorter than any of the following joints . . . . . ? gen. ${ }^{1}$ First joint of the flagellum distinctly shorter than the second, the following cylindrical, at least thrice as long as thick . Heptamerocera Ashmead

\title{
A NEW ORYSSID FROM CHATHAM ISLANDS, BISMARCK ARCHIPELAGO.
}

BY William H. AShMEAD, A. M., ASSistant CURATOR, U. S. NATIONAL MUSEUM.

In a lot of parasitic Hymenoptera, sent to me by Prof. T. D. Alfken, of the Städtisches museum für natur-völker-und handelskunde, Bremen, Germany, was a single male specimen of an oryssid, collected in 1899 by Dr. Hugo H. Schauinsland, in the Chatham Islands, east of New Zealand.

It is an interesting form belonging to a genus not yet known to occur on these Islands, the only other species known from these regions being from Aru.

\section{OPHRYNOPUS SCHAUINSLANDI, sp. nov.}

J.- Length $6.6 \mathrm{~mm}$. Black, the head rugose-punctate with an aeneous black tinge, the forehead tuberculate, the face with two carinae that diverge anteriorly and are connected with a transverse carina bounding the front margin; thorax shagreened; legs wholly black, the hind tibiae serrate on outer face, armed with about I I teeth; the first three being very minute.

The wings are hyaline, with the apical third or more of the front wings fuscous, the stigma and veins being black or brown-black.

The abdomen is as in Oryssus, black and shining, but with the first four or five segments above more or less shagreened and faintly, sparsely, microscopically punctate.

Type in Bremen Museum.

The species is dedicated to Dr. Hugo H. Schauinsland, the Director of the Museum.

1 These genera probably represent males in genera at present known only from the females, and $I$ therefore do not name them. 

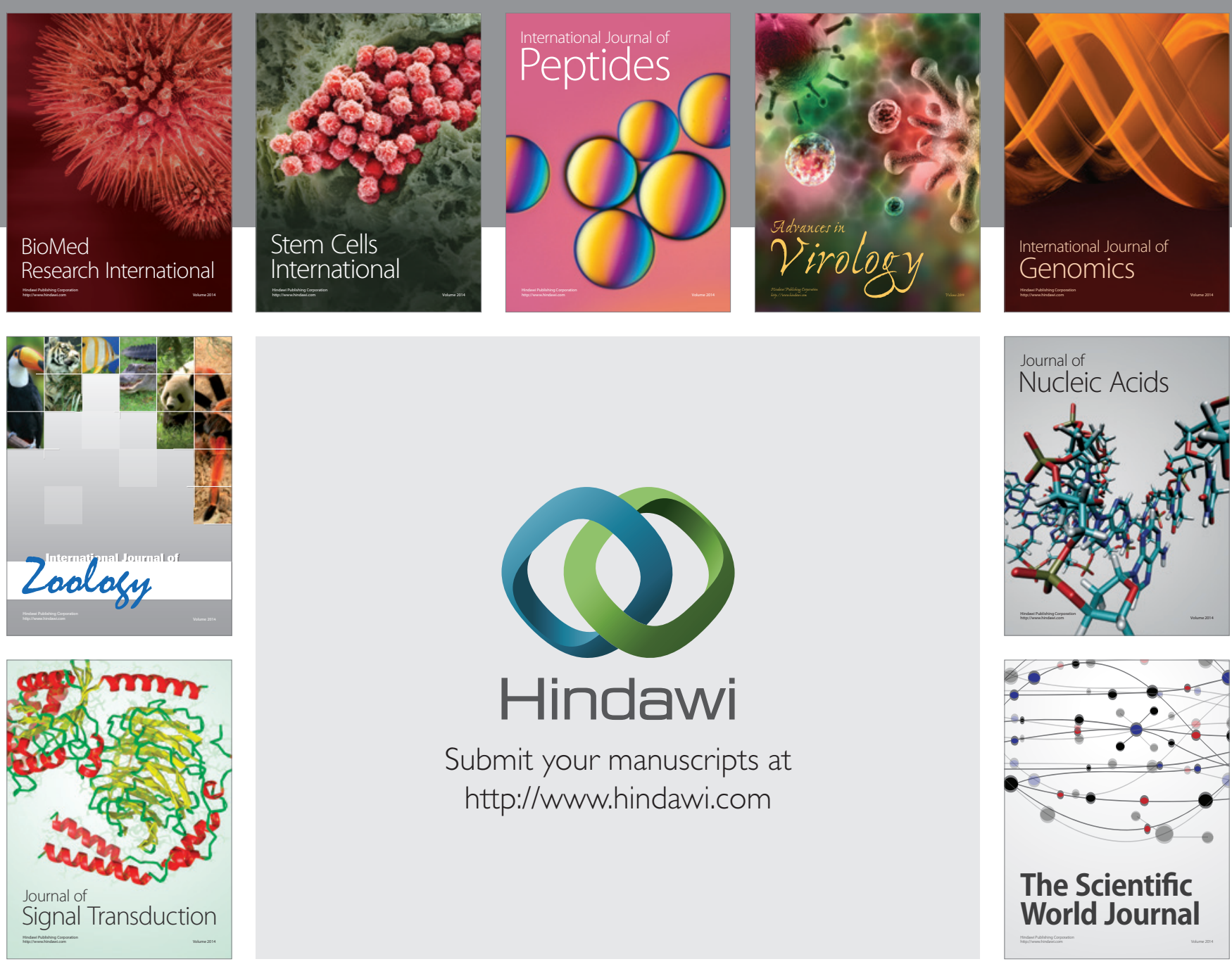

Submit your manuscripts at

http://www.hindawi.com
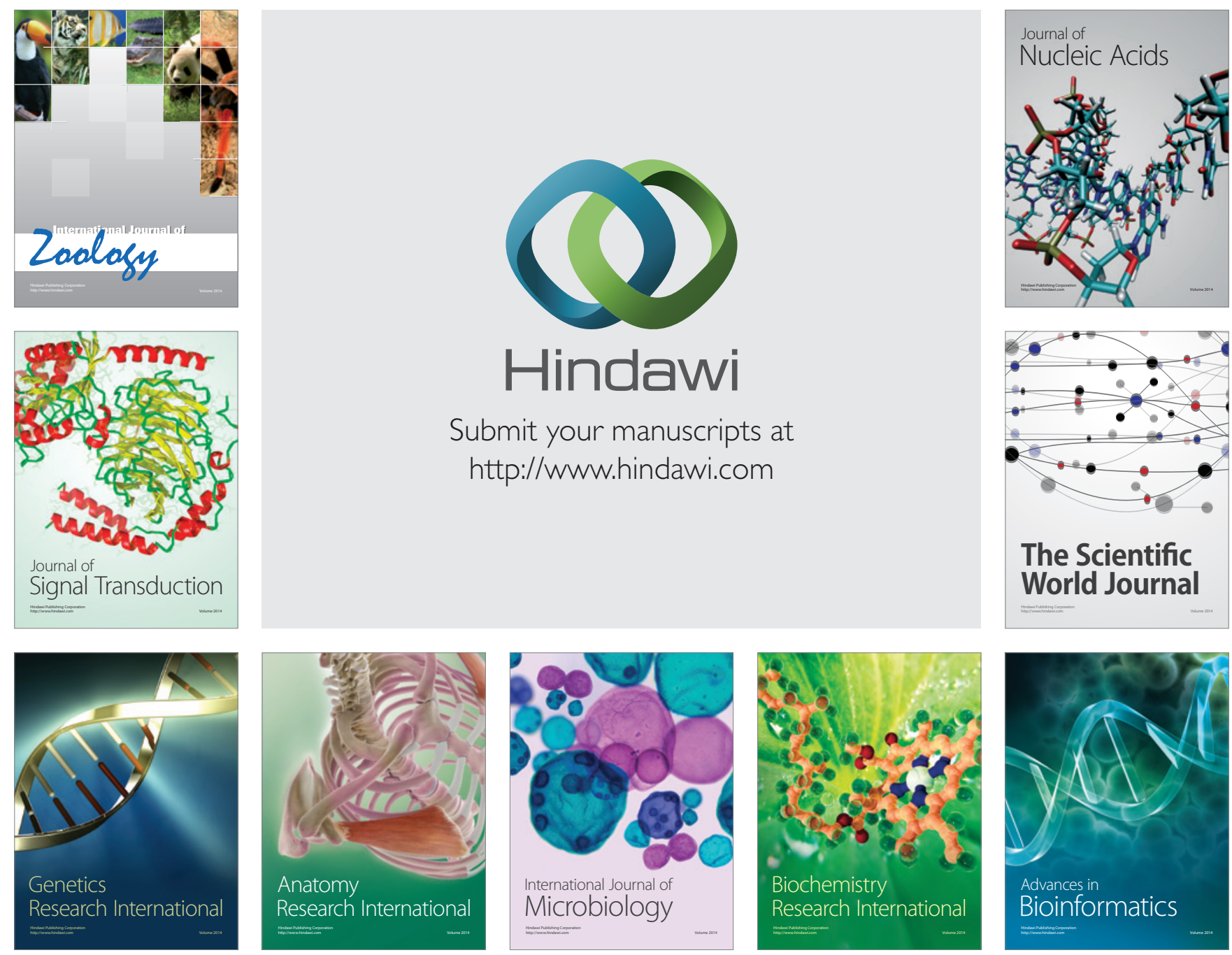

The Scientific World Journal
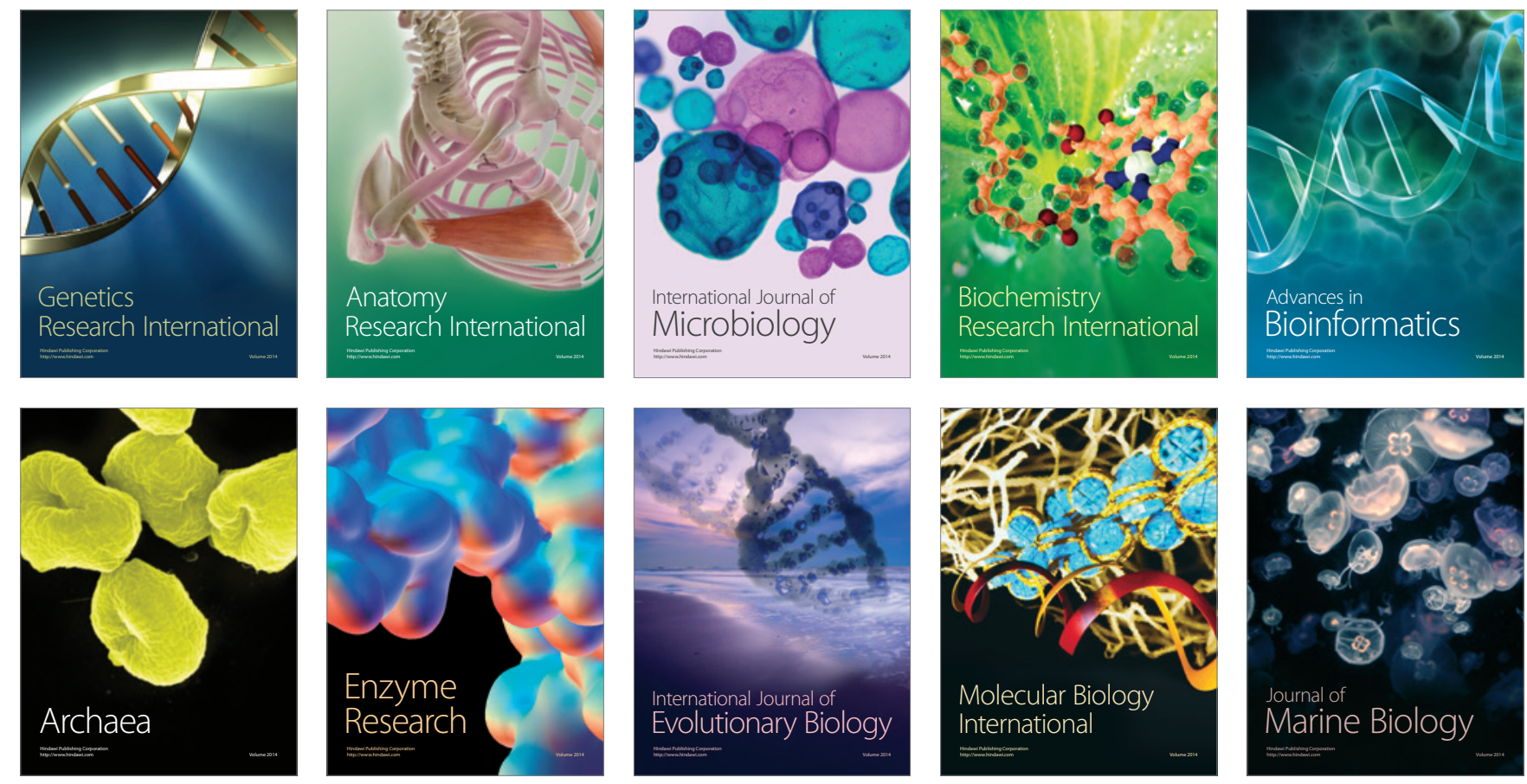